\title{
Quantitative bacterial flora of acute appendicitis
}

\author{
J P ROBERTS
}

Departments of Microbiology and Paediatric Surgery, Southampton General Hospital

SUMmARY A quantitative bacteriological study of the appendix wall of 43 children admitted to this unit showed no significant differences between the flora of the histologically normal and acutely inflamed appendices. Bacteroides species, Escherichia coli, and streptococcal species were the commonest organisms isolated and were found in counts of $10^{3}$ to $10^{8}$ organisms per gram of tissue. Bacteroides species were most commonly the dominant flora in both normal and inflamed appendices.

The lack of increased counts of organisms in acute inflammation of the appendix suggests an unfavourable environment to bacterial proliferation making primary bacterial infection an unlikely aetiological factor in the pathogenesis of appendicitis.

Acute appendicitis is the commonest surgical emergency in childhood, ${ }^{1}$ although its aetiology in most cases is unproved. Most workers have found the qualitative flora of appendicitis does not differ appreciably from that of the normal appendix in adults and children. ${ }^{2}{ }^{3}$ Both Streptococcus milleri and Bacteroides fragilis, however, have been implicated in the pathogenesis of appendicitis by increased isolation rates in acute inflammation. ${ }^{45}$ Less is known of the quantitative flora of the acutely inflamed and normal appendix. In adults anaerobic bacteria are more commonly found in counts of above $10^{6}$ colony forming units $/ \mathrm{ml}$ than aerobic bacteria in acute inflammation, ${ }^{6}$ and anaerobic bacteria, in particular bacteroides species, have been quantified in acutely inflamed and normal appendices. $^{75}$

There are no data of the quantitative flora as a whole from appendix tissue in the normal and inflamed states. This quantitative study was undertaken to show the numerically dominant flora and compare more precisely the flora of the acutely inflamed and histologically normal appendices.

\section{Method}

Forty four children admitted to the paediatric surgical unit at Southampton General Hospital and undergoing appendicectomy between 10 November 1978 and 2 April 1979, were studied. One child who had received antibiotics within two weeks of admission was excluded from the study.

The excised appendix was divided logitudinally and inspissated material removed. One half was sent for histological examination, the other subdivided transversely into tip and proximal sections. The individual sections were weighed, placed in transport medium (Todd Hewitt broth, $0.1 \%$ cystine hydrochloric acid and $10 \%$ glycerol by volume) and homogenised under nitrogen. The homogenate was stored over liquid nitrogen. Serial log dilutions of the homogenate were later made and plated on a selection of media (Mac-Conkey, chocolated, vpt (an agar containing vancomycin, polymixin, and trimethoprim), blood neomycin, and anaerobic agar) and incubated under the appropriate aerobic, microaerophilic, and anaerobic conditions.

Counting was performed with a Gallenkamp colony counter. Dominant isolates were purified by subculturing and identified. Bacteroides species were identified using the Analytical Profile Index $20 \mathrm{~A}$ system $^{8}$ and streptococcal isolates by Lancefield grouping, fermentation of sugars, and growth on special media." 10

Log mean counts for each organism were compared between the inflamed and normal groups by the $t$ test and within individual appendices by the paired $t$ test. Isolation rates between the two groups were compared by the $\chi^{2}$ test.

\section{Results}

Of the 43 children included in the study (age range 5 years 2 months to 15 years 3 months), 29 histologically confirmed cases of appendicitis were found of which four had clinically perforated. Thirteen histo- 
Table 1 Isolation rates and combined counts of anaerobic bacteria in normal and acutely inflamed appendices

\begin{tabular}{|c|c|c|c|c|c|c|}
\hline \multirow[t]{2}{*}{ Organism } & \multicolumn{3}{|c|}{ Histologically normal $(n=14)$} & \multicolumn{3}{|c|}{ Acutely inflamed $(n=29)$} \\
\hline & No $(\%)$ & Counts/g & Mean & No $(\%)$ & Counts/g & Mean \\
\hline Bacteroides fragilis & $3(21)$ & $3 \cdot 1^{7}-1 \cdot 4^{x}$ & $6 \cdot 0^{7 *}$ & $11(38)$ & $1 \cdot 0^{3}-3 \cdot 2^{x}$ & $3 \cdot 2^{7 *}$ \\
\hline Bacteroides thetaiotaomicron & $8(57)$ & $2 \cdot 4^{4}-4 \cdot 2^{x}$ & $1 \cdot 3^{7}$ & $10(35)$ & $1 \cdot 1^{3}-2 \cdot 2^{x}$ & $6 \cdot 4^{7}$ \\
\hline Bacteroides distasonis & $1(7)$ & $1 \cdot 3^{7}$ & - & $4(14)$ & $5 \cdot 8^{5}-2 \cdot 7^{8}$ & $4 \cdot\left(0^{7}\right.$ \\
\hline Bacteroides ovatus & $1(7)$ & $8 \cdot 5^{7}$ & - & $1(3)$ & $4 \cdot 2^{5}$ & - \\
\hline Bacteroides vulgatus & $1(7)$ & $1 \cdot 8^{\mathrm{x}}$ & - & 0 & - & - \\
\hline Clostridium welchii & $8(57)$ & $5 \cdot 8^{1}-1 \cdot 9^{4}$ & $8 \cdot 6^{2}$ & $10(35)$ & $6 \cdot 0^{1}-1 \cdot 4^{3}$ & $4 \cdot 8^{2}$ \\
\hline Anaerobic streptococci & 0 & - & - & $2(7)$ & $9 \cdot 1^{5}-2 \cdot 4^{7}$ & $1 \cdot 2^{7}$ \\
\hline
\end{tabular}

${ }^{*} \mathrm{n}^{\mathrm{x}}=\mathrm{n} \times 10^{\mathrm{x}}$.

Table 2 Isolation rates and combined counts of streptococcal species in normal and acutely inflamed appendices

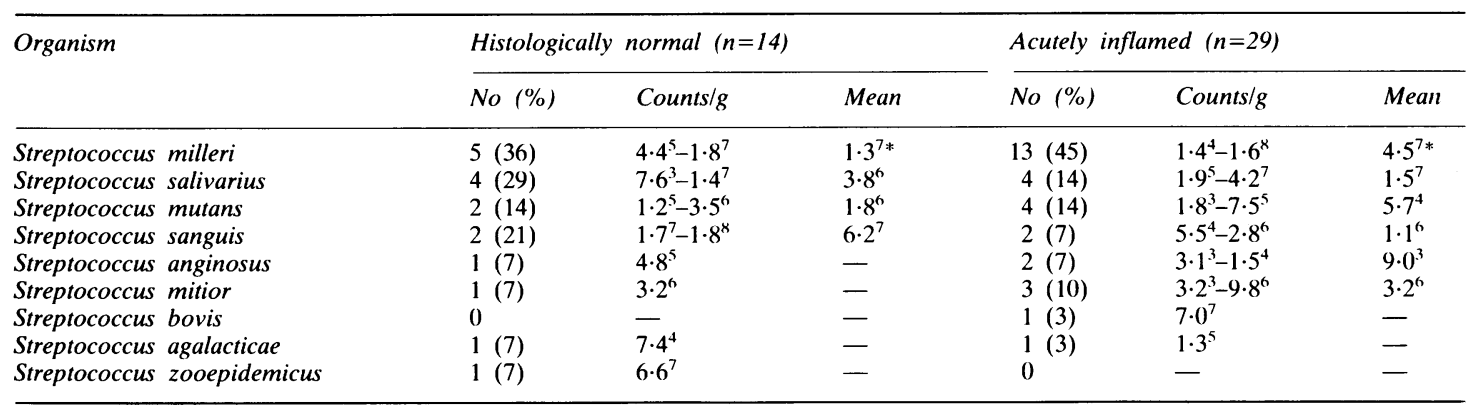

${ }^{*} \mathrm{n}^{\mathrm{x}}=\mathrm{n} \times 10^{\mathrm{x}}$.

Table 3 Isolation rates and combined counts of aerobic bacteria in normal and acutely inflamed appendices

\begin{tabular}{|c|c|c|c|c|c|c|}
\hline \multirow[t]{2}{*}{ Organism } & \multicolumn{3}{|c|}{ Histologically normal $(n=14)$} & \multicolumn{3}{|c|}{ Acutely inflamed $(n=29)$} \\
\hline & No $(\%)$ & Counts/g & Mean & No $(\%)$ & Counts/g & Mean \\
\hline Escherichia coli & $14(100)$ & $1 \cdot 4^{4}-1 \cdot 8^{x}$ & $4 \cdot 4^{6: k}$ & $24(83)$ & $2 \cdot 1^{3}-9 \cdot 7^{7}$ & $1 \cdot 4^{7 *}$ \\
\hline Pseudomonas species & $4(29)$ & $6 \cdot 9^{4}-7 \cdot 2^{6}$ & $1 \cdot 4^{6}$ & $2(7)$ & $5 \cdot 6^{4}-7 \cdot 6^{4}$ & $6 \cdot 7^{4}$ \\
\hline Streptococcus pneumoniae & 0 & - & - & $2(7)$ & $4 \cdot 9^{3}-2 \cdot 0^{7}$ & $8 \cdot 7^{6}$ \\
\hline Staphylococcus aureus & $2(14)$ & $6 \cdot 1^{3}-8 \cdot 1^{6}$ & $2 \cdot 3^{5}$ & $1(3)$ & $1 \cdot 3^{3}$ & - \\
\hline Non-lactose fermenting coliform & 0 & - & - & $1(3)$ & $4 \cdot 3^{5}$ & - \\
\hline Campylobacter & $1(7)$ & $\dagger$ & - & 0 & - & - \\
\hline
\end{tabular}

${ }^{*} \mathrm{n}^{\mathrm{x}}=\mathrm{n} \times 10^{\mathrm{x}}$.

†Counts impossible owing to colony swarming.

logically normal appendices were found at operation and in one case the appendix was removed incidentally.

\section{ISOLATION RATES}

The differing isolation rates of $B$ fragilis, $B$ thetaiotaomicron, and $S$ milleri in the two groups were not significant at the $5 \%$ level (table 1). Neither were there any significant differences in the isolation rates of other streptococcal species, aerobic, or anaerobic bacteria between the two groups (tables 2 and 3). Bacteroides species, E coli, and streptococ- cal species were not isolated in between $10 \%-17 \%$ of acutely inflamed or perforated appendices. There was, however, only one inflamed appendix in which none of these organisms was present (the flora comprised a mixed growth of Haemophilus parainfluenzae and $H$ pneumococcus).

BACTERIAL COUNTS

The counts of the isolated organisms showed no significant differences within individual appendices $(p>0 \cdot 05)$. Between normal and inflamed appendices there was no significant difference in the counts of 


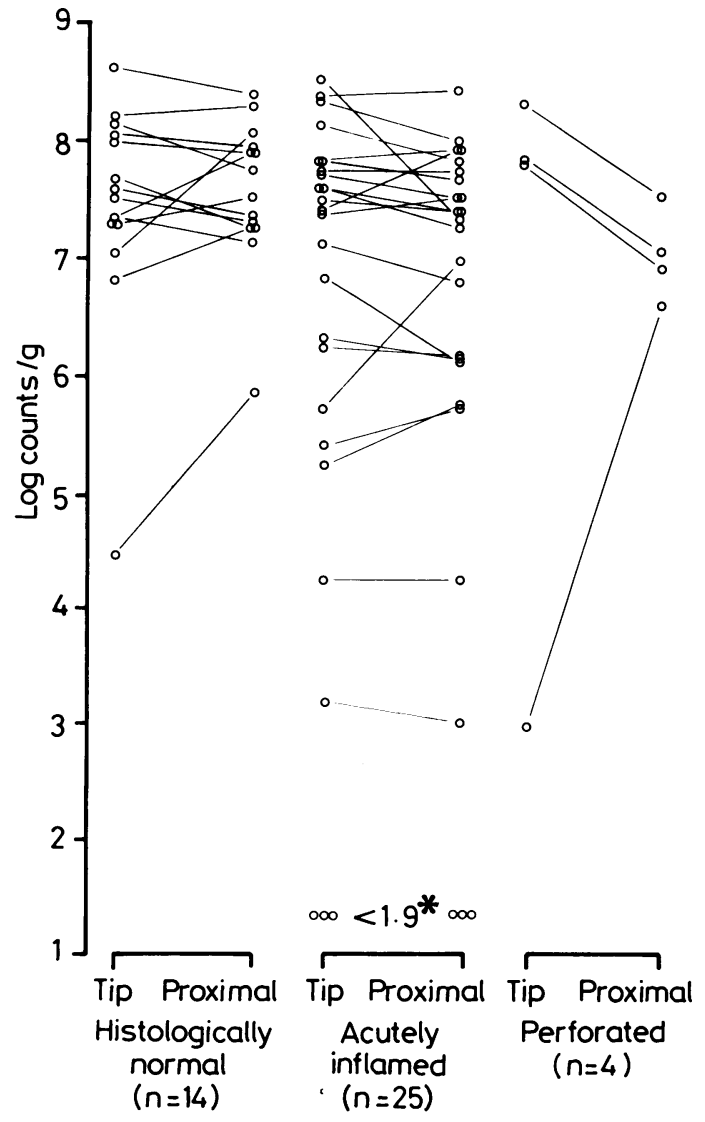

Fig 1 Log colony counts of tip and proximal sections for all bacteroides species in each group of appendices.

*Minimum sensitivity of method when organism not isolated.

all streptococcal isolates $(0 \cdot 05<\mathrm{p}<0 \cdot 1)$, but the difference was significant for $E$ coli and the combined bacteroides species $(0 \cdot 02<p<0 \cdot 05)$. This difference was not apparent if the appendices in which the organism was not isolated were excluded from the comparison (figures 1, 2, and 3). Tables 1 , 2 , and 3 also indicate the range of counts found for individual organisms in each group of appendices.

DOMINANT BACTERIA

Table 4 shows that bacteroides species were the predominant organisms in most normal and acutely inflamed appendices.

\section{Discussion}

This study confirms no qualitative difference in the flora of the acutely inflamed and normal appen-

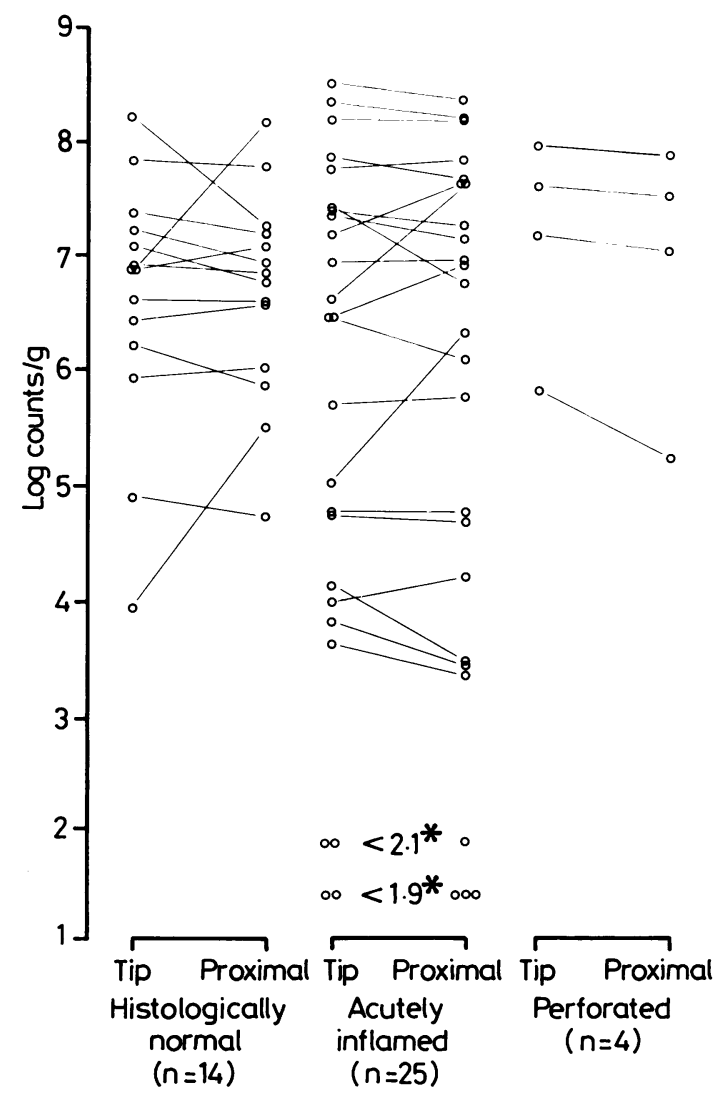

Fig 2 Log colony counts of tip and proximal sections for all streptococcal species in each group of appendices. * Minimum sensitivity of method when organism not isolated.

dices, $E$ coli and bacteroides species being the commonest aerobe and anaerobe respectively, in both groups. Isolation rates are very variable depending on the site cultured and methodology. ${ }^{11}$ Ghnassia et al, for example, isolated bacteroides species from only $2 \%$ of luminal swabs. ${ }^{3}$ The method of grinding of the appendix wall, combined with methods to preserve anaerobes during processing, enables high isolation rates of all organisms.

The age range in this study differs from most qualitative and all quantitative studies, which have tended to use adults, or adolescents and adults. Although it is highly likely that the bacterial flora is similar in all these age groups, this has not been verified. In addition to variation in technique, this makes valid comparisons between this and other studies more difficult.

No significant difference in the isolation rates of $S$ 


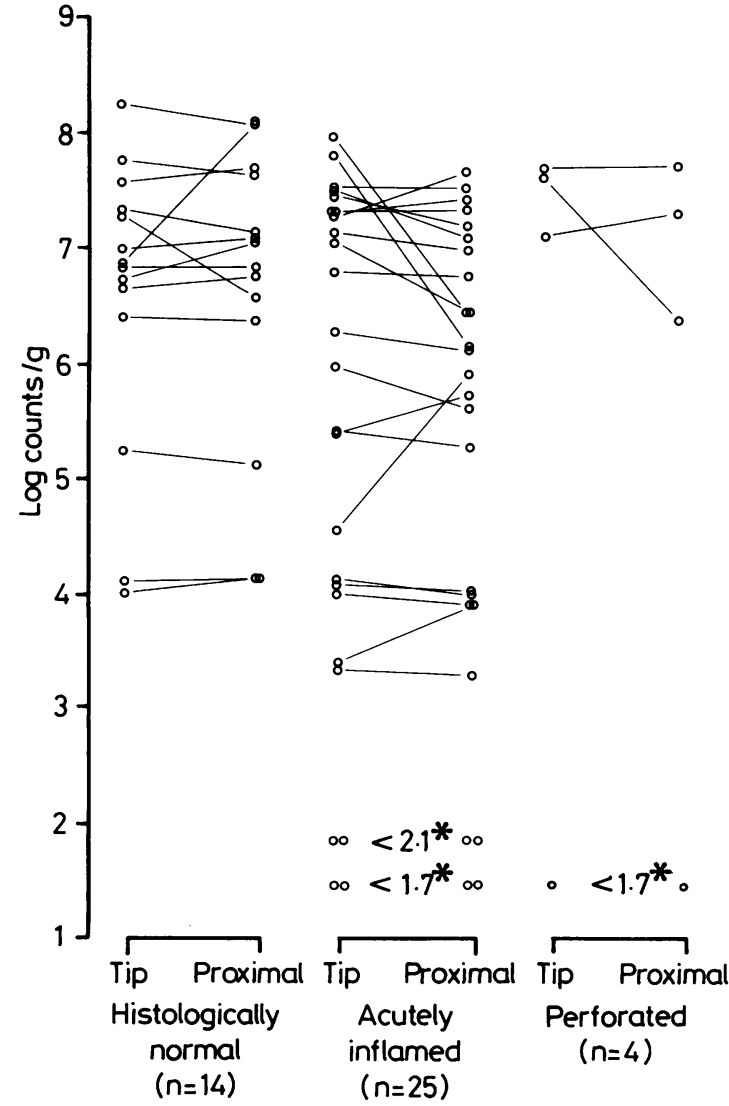

Fig 3 Log colony counts of tip and proximal sections for Escherichia coli in each group of appendices.

* Minimum sensitivity of method when organism not isolated.

milleri between normal and inflamed appendices was found, contrary to Poole and Wilson who found this organism in $30 \%$ of 13 normal and in $60 \%$ of 79 acutely inflamed appendices in the under 20 years age group. ${ }^{4}$ The appendix, however, has been confirmed to be an important reservoir for $S$ milleri, which is a common pathogen in postappendicectomy sepsis in children. ${ }^{12}$

The most comparable studies of the anaerobic bacterial flora of the appendix have been carried out in two studies by Werner et al. ${ }^{5}$ They made a quantitative study of the luminal contents of 49 acutely inflamed appendices and 11 incidental appendicectomies and found bacteroides species in $87 \cdot 8 \%$ of acutely inflamed appendices, with counts of between $10^{3}-10^{9} / \mathrm{g}$ and in all incidental appendices with counts of $10^{4}-10^{10} / \mathrm{g} .^{57}$ The acutely inflamed appendices were from all ages and the incidentals from women undergoing gynaecological laparotomy. The counts obtained by Werner et al were similar to those found in this study.

In the same studies $B$ fragilis was detected in $80 \%$ and $B$ thetaiotaomicron in $55 \%$ of acutely inflamed appendices, compared with normal large bowel flora where $B$ thetaiotaomicron predominates and $B$ vulgatus is found in $43 \%$ of cases. This study shows an apparently increased isolation rate of $B$ fragilis in acute inflammation (from $21 \%$ to $38 \%$ ) but this was not found to be significant. More recently Elhag et al found an identical isolation rate of $41 \%$ for $B$ fragilis in normal and acutely inflamed appendices. ${ }^{2}$ Although this would appear to exclude $B$ fragilis as a primary pathogen in appendicitis, it undoubtedly has an important role as a secondarily invasive organism causing appendicial sepsis. ${ }^{26}$

The consistently lower isolation rates for bacteroides species in this study, compared with those of Werner et al is most likely due to only the dominating Gram negative anaerobe in each case being identified.

The counts of bacteroides, E coli, and streptococci when present in the appendix, do not significantly differ between the normal and acutely inflamed state, although the tissue ischaemia in acute appendicitis would be expected to favour overgrowth of anaerobic and microaerophilic organisms. ${ }^{13}$ The lack of increased counts in acute inflammation suggests that the environment for bacterial proliferation is unfavourable. In addition, as grinding of the appendix would be expected to

Table 4 Numerically dominant organisms of the appendix flora in histologically normal and inflamed appendices

\begin{tabular}{|c|c|c|c|c|}
\hline \multirow[t]{2}{*}{ Organism } & \multicolumn{2}{|c|}{ Histologically normal $(n=14)$} & \multicolumn{2}{|c|}{ Acutely inflamed $(n=29)$} \\
\hline & No & $\%$ Dominant & No & $\%$ Dominant \\
\hline All bacteroides & 14 & 93 & 26 & 76 \\
\hline Bacteroides fragilis & 3 & 21 & 11 & 35 \\
\hline Bacteroides thetaiotaomicron & 7 & 50 & 10 & 28 \\
\hline Bacteroides distasonis & 1 & 0 & 4 & 10 \\
\hline All streptococcal species & 14 & 0 & 25 & 10 \\
\hline
\end{tabular}


liberate all organisms to the homogenate, the lack of increased counts suggests that the number of organisms invading the wall is low in comparison with those in the lumen or mucosally associated. This would favour the spread of bacteria through the appendix wall during inflammation as being a passive process secondary to the loss of viability of the wall as has been shown to occur with obstruction of the lumen. ${ }^{1+15}$

I would like to thank Professor P Watt and Mr D Drake for their invaluable advice and guidance in this work, and Mr NF Freeman for his encouragement and advice in preparing this paper.

\section{References}

1 Jones PF. Emergency abdominal surgery. Oxford: Blackwell, 1974:207.

2 Elhag KM, Alwan MH, Al-Adnani MS, Sherif RA. Bacteroides fragilis is a silent pathogen in acute appendicitis. $J$ Med Microbiol 1986:21:245-9.

${ }^{3}$ Ghnassia JC, Ridoux G, Berche P, Veron M, Pellerin D. La flor bacterienne endappendiculaire chez l'enfant. Arch Fr Pediatr 1978:35:262-8.

+ Poole PM. Wilson G. Streptococcus milleri in the appendix. J Clin Path 1977:30:937-42.

5 Werner H, Kunstek-Santos H, Schockermohle C, und Gundurewa. Bacteroides und appendizitis. Pathologia et Microbiologia (Basel) 1975;42:110-18.

- Pieper R, Kager L, Weintraub A, Leindberg AA, Nord CE.
The role of Bacteroides fragilis in the pathogenesis of acute appendicitis. Acta Chir Scand 1982;148:39-44.

${ }^{7}$ Werner H, Seegler HP. Kulturelle untersuchungen uber den keimgehalt der appendix unter besonderer berucksichtigung der anacrobier. Zenkalblatt fur bakteriologie parisitenkunde infektionkrankheiten und hygiene Erste Astechung original 1963; 188:345-64.

${ }^{x}$ Moore HB, Sutter VL, Finegold SM. Comparison of 3 procedures for biochemical testing of anacrobic bacteria. J Clin Microbiol 1975;1:15-24.

"Cowan ST, Steel K. Manual for the identification of medical bacteria. 2nd ed. Cambridge: Cambridge University Press, 1974:51-6.

11 Ball LC, Parker MT. The cultural and biochemical characters of Streptococcus milleri strains isolated from human sources. Journal of Hygiene (London) 1979;82:63-78.

"Lau WY, Teoh-Chan CH, Fan ST, Yam WC, Lau KF, Wong $\mathrm{SH}$. The bacteriology and septic complications of patients with appendicitis. Ann Surg 1984;200:576-81.

12 Madden NP. Hart CA. Streptococcus milleri in appendicitis in children. J Pediatr Surg 1985;20:6-7.

13 Mims CA. The pathogenesis of infectious disease. London: Academic Press, 1970:71.

14 Pieper R, Kagler L. Tidefelt U. Obstruction of the appendix vermiformis causing acute appendicitis, an experimental model in the rabbit. Acta Chir Scand 1982;148:63-72.

15 Wangensteen $\mathrm{OH}$, Dennis C. Experimental proof of the obstructive origin of appendicitis in man. Ann Surg 1939;110: $629-47$.

Correspondence to Mr JP Roberts, Wessex Regional Centre for Pacdiatric Surgery, East Wing, Southampton General Hospital, Southampton SO9 4XY.

Accepted 2 December 1987 